How to cite: Moldovan, A.M., Bratanovici, C. (2020) Monitorisation of Medias Hydrotecnical System in Order to Optimise Requirements for Water Use. 2020 "Air and Water - Components of the Environment" Conference Proceedings, Cluj-Napoca, Romania, p. 169-176, DOI: 10.24193/AWC2020_16.

\title{
MONITORISATION OF MEDIAS HYDROTECNICAL SYSTEM IN ORDER TO OPTIMISE REQUIREMENTS FOR WATER USE
}

\author{
Adriana M. MOLDOVAN ${ }^{1}$, Cristian BRATANOVICI ${ }^{1}$
}

DOI: 10.24193/AWC2020_16

\begin{abstract}
Water is part of the great triad that gives and sustains life on earth: water, air, and soil. The disappearance of any of these elements also generates the disappearance of life. In the case of water, the National Administration "Apele Române" takes care of the management of the national resources, both qualitatively and quantitatively. Knowing that the water management has to be efficient and prompt as possible, borned the idea of an integrated system that allows this to happen quickly and correctly, called the WATMAN system. This system includes, in an operational way, the entire Romanian qualitative and quantitative water management activity, giving the possibility to take urgent and necessary decisions in different moments of crisis. In order to do that data surveillance and processing must be constant. This is why quality and quantity sensors will be installed in relevant locations. This data will be sent to regional dispatch centers, where after being processed and correlated, staff will be able to make the appropriate decisions for the good management of this important resource that is water.

Quantity and quality sensors will be distributed across the 51 stations spread across the national perimeter that will be connected to the 11 regional dispatch centers of the ABAs across the country. At the ABA level, the data received from sensors will be stored in a database and processed in order to take urgent water management decisions. In order to be able to go through this complex system it is necessary to have special programs for each category of data (qualitative and quantitative), water flow rate, accumulation volume, groundwater and surface water quality, which would allow the results to be correlated and the decision taken.
\end{abstract}

Keywords: hydrotecnical system, information system, water quality

\section{INTRODUCTION}

Water related problems in water management needs to be known in all its aspects in order to find solutions. This is the purpose of the national water management system, subdivided into 11 corresponding areas of 11 large catchment basins, the

\footnotetext{
${ }^{1}$ PHD student, engineer at National Administration "Romanian Waters", Basinal Water Administration of Mureș - Romania, Tîrgu Mureș, str. Koteles Samuel nr. 33; e-mail adress: adrymoldo@gmail.com ; cristian.bratanovici@rowater.ro
} 
management of which is entrusted to basin water administrations. They are the ones that primarily manage the surface water and underground water resources and protect them both qualitatively and quantitatively ([1], [2]).

The Mureş Basin Administration, which manages the river basin of the Mureş River, has an important role to play.

Located in the center of Romania and running towards the West, the Mureş basin has a total area of $28310 \mathrm{~km}^{2}$, i.e. $11.7 \%$ of the total area of the country; Mures River, from the spring to the Hungarian border, has a length of $761 \mathrm{~km}$, and in this area, there are $11,119 \mathrm{~km}$ of coded water courses, that means courses managed by the State, through the National Administration "Apele Române" ([4]).

Although appearances could lead us to the idea that it is only the care and protection of surface water, the same care is enjoyed by the underground waters of the entire basin. In order to ensure the protection of the population against water excesses, $832,614 \mathrm{~km}$ of dikes, $1131 \mathrm{~km}$ of river water treatment works, $511,042 \mathrm{~km}$ of consolidation and bank defenses, 7 permanent accumulations with a total volume of 139,16 million $\mathrm{m}^{3}$ have been built.

The comfort and especially the safety of the inhabitants decreases when the water is in excess or in deficit, both qualitatively and quantitatively. So we can find us in the following extreme situations:

- from a quantitative point of view, we can find ourselves in surplus situations when we have to face floods, housing and socio-economic destruction - or deficient ones - when water shortages endanger the supply of water to population, agriculture and industry;

- from a qualitative point of view, if quality is diminished, it can result in pollution that could endanger people's lives and flora and fauna habitats around the watercourses.

With all these problems, presented synthetically, the water decision makers have to manage the situation.

\section{WATERCOURSES MONITORING}

Excess and water scarcity must be balanced and the consumption of this natural resource must be optimized and managed in such a way that each use is satisfied and its evictions in the emissaries are controlled. For this purpose, continuous monitoring of all watercourses as well as groundwater is carried out in such a way that the necessary resource can be always controlled and ensured. Hydraulic retention works (accumulations, polders) are kept under observation, both in terms of the amount of water accumulated and in terms of their stability and functionality. The territory of the Mureş basin is monitored by means of hydrometric stations, located in places considered eloquent.

All the information received from these stations is sent to the system dispatchers, processed and centralized at the basin administration's dispatch center in Tîrgu 
Mureș and communicated to all decision-making teams. The fig. 1 shows the daily flow of hydrological data in the Mureș basin.

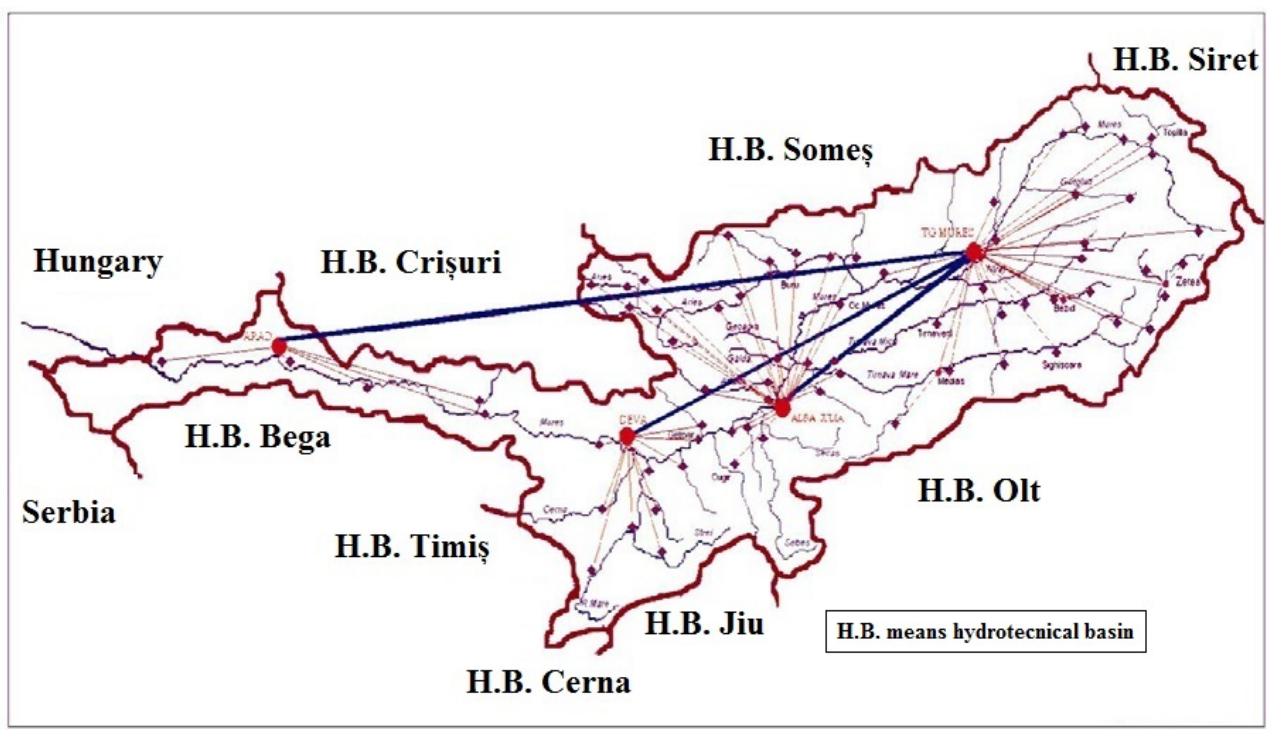

Fig. 1. Daily informational flow in Mureș basin

\section{IMPLEMENTATION OF THE INFORMATIONAL SYSTEM}

In order to make the entire process of data collection, communication, processing and decision operational, starting with 2013, a computer system called WATMAN (water management) is implemented at the level of the entire Romanian Water Administration ([3],[4]).

It has the ultimate goal to improve the comfort and safety of people's lives and to ensure the monitoring of the environmental protection. A final and effective instrument will be provided to decision-makers in the event of disasters (floods or pollution), and residents in vulnerable zones will benefit from a prompter alarm and intervention.

In addition to existing stations, but also outside, stations equipped with sensors will be mounted to transmit the information according to the information flow scheme. There will be stations with sensors for measuring the temperature, flow rates and water levels, rainwater stations for measuring solid precipitation but also sensing stations able to determine any change in the structure of the flood defense works and at the same time to alert the population to possible situations damage.

The WATMAN computer system includes the following processes: E-Sensor, Parametric, Hydroshield, Reports and V-Struct, each with its algorithm and software program. 
E-Sensor is the most complex process and involves: management of station groups, accumulation capacity curves, limnometric keys, threshold alerts, management of maneuvers to be applied in houses with baths.

An important attribute of the E-Sensor process is to allow maneuvers to be managed in order to create them from the headquarters of the administration to accumulation, to request a maneuver from the storage to the premises, and the possibility of accepting or rejecting it.

The same E-Sensor process is designed to analyze documents such as graphs or operating regulations for a certain accumulation.

The Parametric process allows the administration of layouts, measuring and control devices, makes it possible to enter the measured values manually and to view the latest values entered as well as those entered manually in graphs or tables.

Hydroshield is a complex of processes applied to the hydrological field, especially pollutants that allows:

- alerts to a contact list

- Managing interventions and placing them on the map

- managing the owners and subordinate objectives

- managing the "pollution" mode by introducing reported events into the base

- issuing reports (system status, operative, synthesis, calamity report, centralizing the cost of interventions)

Reports is a Watman subsystem that, by name, is repeated in appearance because it allows, issuing different reports. But if in the other subsystems, we find reports specifically concerning a subunit of the basin administration, in this case we have to deal with reports whose data arrive from the subunits and centralize them for the ABA headquarters. The subsystem allows:

- receiving a report on the managed objectives, subordinated to each organization

- obtaining an intervention report covering all interventions grouped on water management systems or on the administration

- obtaining a report on the existing objectives (dams, cantons, dikes, work groups)

- getting a report on all the alerts that were active

- obtaining a report on exceedances of the normal hydrological threshold

- obtaining the ratio of water volumes in the main accumulations (this report is run at ANAR level).

The next component of the Watman system is the $\mathbf{V}$-Struct process that allows control and observation of the entire Watman functional structure and its state.

V-Struct allows to display alerts in manner that they can be filtered; allows viewing existing layers (dams, stations, etc.); reports on widespread precipitation at national level, with extracts of the most significant ones ([5], [6]). 


\section{MEDIAS HYDROTECHNICAL MONITORING SYSTEM}

The Mediaş Hydrotechnical System (Fig. 2) is part of the Mureș Water Management System, belonging to the Mureş Water Basin Administration, and is part of the river basin of the Târnava Mare. The system headquarters are located in the city of Mediaș, in the immediate proximity of the permanent retention of Ighiş.

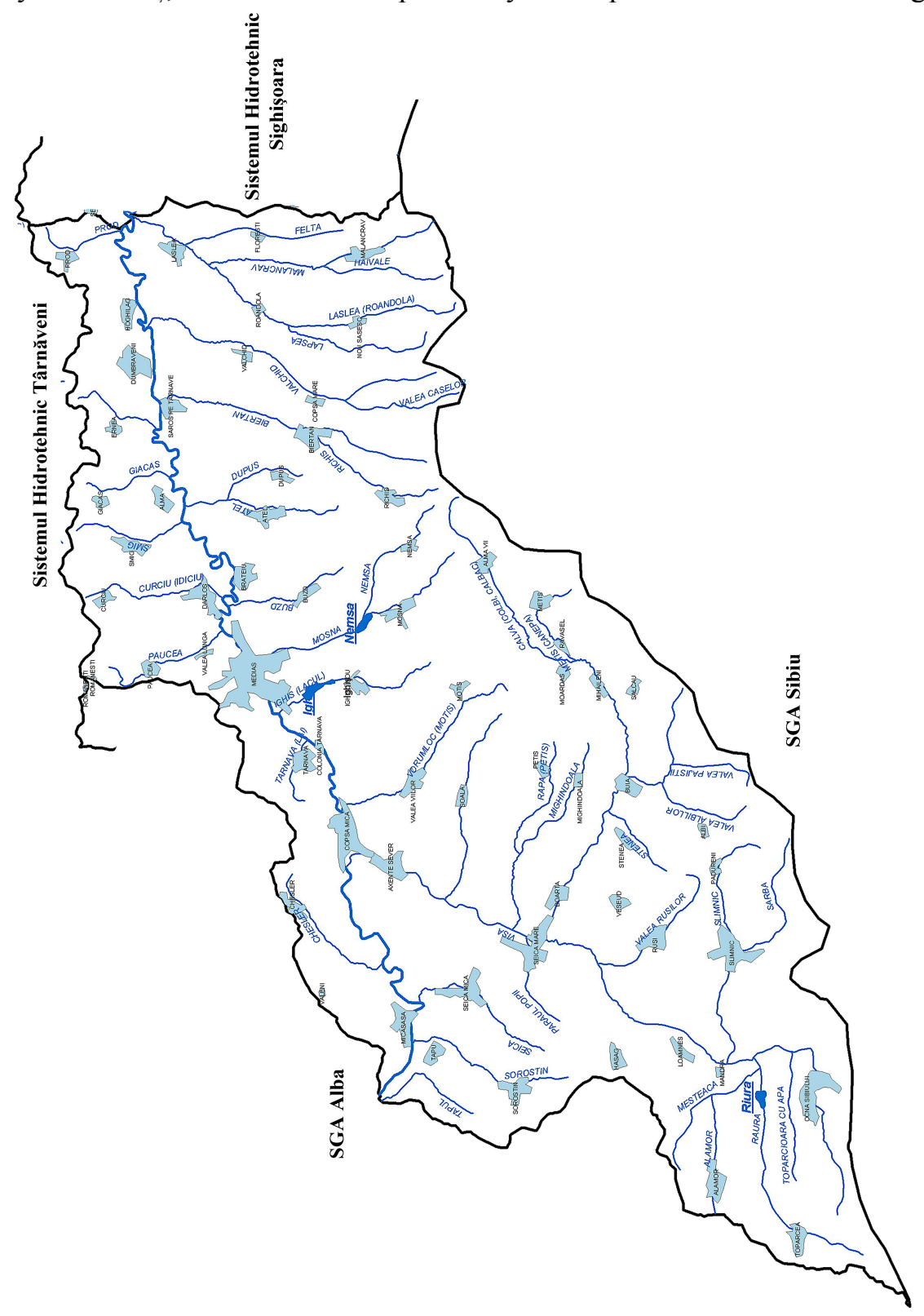

Fig. 2. Mediaș hydrotecnical system drainage network 
In addition to classical flood defense works, the system includes two reservoirs: 1. Nemşa, wich is a non-permanent reservoir, designed to mitigate floods by occasionally collection of excessive flows that may appear on the Moşna River; 2. the permanent reservoir of Ighiş, located on the Ighiş river. The reservoir of Ighiş has to be permanent because the volumes of water accumulated here are destined at the same time for human and technological consumption in the downstream localities (by example of Copşa Mică).

For the coordination of debit deliveries, the operating regulations of the two dams are used, as well as the data obtained from the hydrological stations on the main water course, Târnava Mare, respectively Mediaş and Şeica Mare.

For the Mediaş hydrotechnical system, the Watman computer system involves the installation of sensors at the Mediaș and Şeica Mare hydrometrical stations, as well as at the dams of Nemşa and Ighiş. Primary interests are related to the volume of defluent water in the reservoir and the stability of dams. For this reason, the Watman system provides the installation of the volume sensors as well as those on the technical state of the dam. At the same time, there are control sensors at the bottom drainage valves, where excess or necessary flows are discharged, controlling their opening.

The entire database consists of the measurements transmitted by the precipitation (liquid and solid) sensors, temperature, flow, level at the hydrometric stations, as well as those from Nemşa and Ighiş reservoirs to the system dispatcher and of the administration. This transmission is made using the E-Sensor system.

\section{CONCLUSIONS}

In the past, data collection for the operation of a reservoir or of a whole hydrotechnical system was done manually, through periodic readings. These data are still centralized (Fig. 3) and periodically sent to basin dispatcher, which has the task of processing and transmitting them to the decision-making units.

In parallel with this work, the introduction of modern, computerized (Watman system) methods allows faster and more accurate readings, more prompt transmission, and more rapid alert of the population in imminent disasters. At the same time, it is also possible to automatise the controls of the valves / booths that need not more to be manual.

Apart from the fact that the water management of the entire water management process through the WATMAN computer system responds with priority to human space security requirements, such as to protect them against any disaster, in times of normal operation of water management systems. In the same way it can provide an opportunity to optimize the satisfaction of all water requirements taking into account the protection and maintenance of fauna habitats in good conditions.

Although the automation of the entire process involves long-lasting work related to the mounting of hardware structures (location of stations, sensors, control elements, etc.), as well as to the design and application of the so-called software part, 

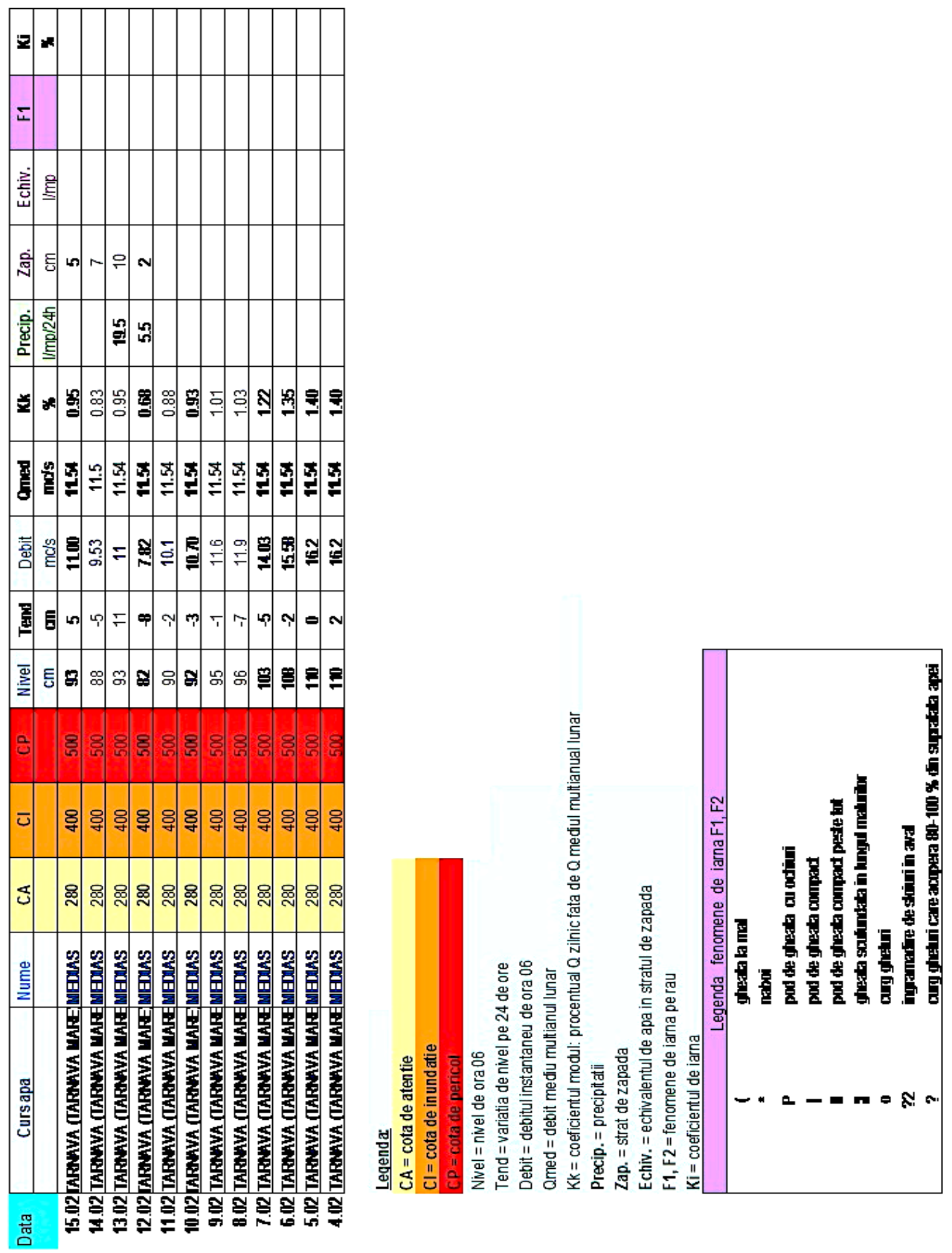

Fig. 3 Hydrological data taken at the Mediaș station betveen 4.02 and 15.02.2019

its application will optimize all water management. By increasing the precision of measurements (both quantitative and qualitative) and their operability, the safety of 
the lives of the inhabitants of the flood-protected areas, the socio-economic objectives, the timely decision on the execution of new works and the increase of the degree of environmental protection.

\section{REFERENCES}

1. Bădăluță M.C., Gospodărirea apelor mari, URL: https://www.ct.upt.ro/studenti/cursuri/badaluta/Cap_4.pdf, accessed on 17.02.2019

2. Colceriu R., Strategia și concepția împotriva inundațiilor în spațiul bazinului hidrografic Mureș, URL: https://www.limnology.ro/water2010/Proceedings/21.pdf, accessed on 18.02.2019

3. Dodescu G., Oancea B., Răceanu M., Procesare paralelă, Ed. Economică, 2002

4. Gabor O. și colectivul - Watman sistem informațional pentru managementul integrat al apelor, Revista Hidrotehnica nr. 2 - 3, vol. 50, 2005

5. Popa D., (2018), Introducere în rețele de calculatoare, Editura Eikon,

6. Popescu E., (2014), Algoritmi. Teorie și aplicații, Editura Else 